\title{
II
}

\section{TOXIC JAUNDICE AND ANTI-SYPHILITIC TREATMENT}

\section{Discussion}

Dr. David NABARro said that as most of his work had been in connection with children he had not had many cases of toxic jaundice. He could remember only one case out of many hundreds of children whom he had treated with injections. Children's livers were more healthy than those of adults : indeed, he supposed that, generally speaking, the tissues of children were in a healthier state than those of adults.

As to whether these drugs should be used when disease of the liver was present, he remembered one case in which a child had an enlarged syphilitic liver, and was treated with small doses of mercury. This went on for some years, and then his opinion was asked as to whether it was safe to give salvarsan. He gave the boy sulfarsenol intramuscularly ; there was improvement, the liver went down, and to-day he was a healthy athletic youth.

With regard to cases of delayed toxicity of the liver following such administrations after a long interval, he did not feel sure that the cases which Sir William Willcox had cited could be attributed to the salvarsan. He did not see how one could be sure that the condition had not arisen as a result of one of the other causes of toxic liver. An interval of one year or one and a half years after the giving of $\mathrm{NAB}$ was rather too long to justify the statement that these were cases of delayed poisoning. As for bismuth, although it was quite likely that bismuth might cause toxic effects on the liver, he had not seen any cases of jaundice occurring in children after bismuth administration.

DR. T. ANWYL Davies said how pleased he was to have heard such an authority on the subject as Sir William Willcox. He had never seen a case of this kind in a child, but he had seen dermatitis following bismuth, and it seemed to him that syphilologists could not ignore the other organs of the body in discussing toxic effects. 


\section{JAUNDICE AND ANTI-SYPHILITIC TREATMENT}

Possibly dermatitis, of which one saw a fair amount, might be due to a similar process in other internal organs of the body. Possibly with dermatitis there might be a mild reaction of the liver to arsenobenzene.

There was a certain amount of experimental evidence suggesting that liver extract might be useful in jaundice and dermatitis. At the Whitechapel clinic this had been proved to be correct.

He had been very pleased to hear Sir William Willcox advocate glycogen in poisoning of the liver. Since Craven, in America, published his paper recommending the prophylactic giving of protein and fat but not glucose to prevent intoxication of the liver, there had been a tendency to discard the administration of glucose in favour of proteins and fats, and so he had been glad to hear Sir William recommend glucose. There was so much experimental and clinical evidence in support of that procedure that he rather suspected the truth of the foundations of Craven's paper. Craven's work was done on dogs. Several laboratory workers stated that one of the chief things to upset a dog was to give it carbohydrates; so that Craven, perhaps, chose the wrong animal for experiment.

Sir William Willcox had laid great stress on the dangers of the administration of arsenic. At the Whitechapel clinic a heavy course was given -0.75 grammes per week over a period of thirteen weeks, with only one three-weeks' interval. That was considered to be a very heavy course, as the average course only totals 5 or 6 grammes. But in spite of such a heavy course there had been only six cases of jaundice in twenty-one months, although an average of 14,000 injections of an arsenical compound were given per annum. Three of these jaundice cases were obviously of the catarrhal type; only two were clinically an arsenical toxic jaundice, and these were not severe; there were no deaths. That incidence was not quite as heavy as the incidence in most of the clinics in England.

Dr. Anwyl Davies emphasised the time factor in relation to dosage as of great importance in poisoning of the liver and accumulation of the drug. He suggested that the body tissues, when a regular course of arsenic was given, became accustomed to deal with the arsenic, provided that arsenic was not given in too heavy doses. He thought the 


\section{BRITISH JOURNAL OF VENEREAL DISEASES}

patients did become accustomed to deal with the arsenic, and then if the intervals of rest were too frequent, although during each rest the arsenic in the body was being excreted, the tissue cells at the same time lost their acquired power to deal with arsenic or the arsenobenzene radicle. Did anaphylaxis play a part?

In his own clinic, if a case of jaundice was found and the spirochæte was active, he and his colleagues continued with bismuth, though they stopped the arsenic.

Mr. Hamish Nicol asked whether there was any simple clinical test by which the liver function could be estimated during the course of the injections.

Mr. V. E. LLOYD said that in his clinic at Guy's Hospital it was found that toxic jaundice among women was extremely rare. Occasionally a case in a child was seen, but these children were usually at the age of puberty or a little earlier. The various liver function tests at disposal were only positive when the damage to the liver was rather gross. The Van den Bergh test had proved the most useful. But if care were taken, liver damage could be mostly detected by close clinical observation almost as soon as it could be by the Van den Bergh test. The chief early symptoms were minor and repeated gastric disturbances, skin rashes which came on rather late in the course of treatment, slight loss of weight, and some depression. There were also complaints of pain in the back. When this last symptom showed itself it put one very much on the qui vive.

A certain number of cases of anthrax came to Guy's, as the hospital was near a tanning district. During the last few years it had been the custom to treat these cases with arsenobenzol, the average dose being $\mathrm{I} \frac{1}{2}$ grammes $\mathrm{NAB}$ within thirty-six hours. $\mathrm{He}$ had seen no toxic effects from such doses, nor any indication of liver upset.

One interesting line of investigation concerning clinic patients was in connection with the calcium metabolism. The addition of calcium to the diet was thought to have some protective effect. He had treated a certain number of cases by calcium therapy from the prophylactic point of view, and during the last few months calcium lactate or calcium gluconate had been given orally during intervals between arsenobenzol injections.

He had treated a certain number of cases with bismuth alone, and had never seen a jaundice in which bismuth 


\section{JAUNDICE AND ANTI-SYPHILITIC TREATMENT}

alone seemed to be the cause. His impression was that during the years after the war in his own hospital arsenobenzol jaundice cases were not common, but when they did occur they were particularly severe, whereas of recent years they had been more common though less severe.

Lieut.-Colonel E. G. FFrench said that in his experience in the Army there were two types of jaundice: the first a simple jaundice due to the spirochæte, and the other a very severe type of jaundice after these patients had had arsenical treatment. These cases were seriously ill throughout. With regard to the causation of the jaundice it was an idiosyncrasy in many cases. At Rochester Row he did not think he saw more than two cases of jaundice, but at Dublin and in France he came across many more cases. One possible reason was that in London the cases were treated in the wards, whereas in Dublin there were two separate buildings and the patients had to walk across a yard to get back to their quarters after treatment. In France also they were liable to be exposed to cold and wet, and this contributed to jaundice.

Among the appearances recorded post mortem were the paleness and softness of the spleen, the structure having become unrecognisable: the swelling of the cortex of the kidneys, with the capsule not adherent, and the weight of the liver about $25 \mathrm{oz}$. In treating with bismuth he had not found one case of jaundice.

COLONEL HARRISON said most of the points which he had intended to touch upon had been dealt with already by other speakers. The more he had to do with arsenobenzene jaundice the more perplexed he became. He had thought that dosage was probably one of the most important factors and certainly the higher the individual dose the greater the incidence of jaundice. At the same time he thought that sufficient attention had not been paid to the X-factor which was mentioned by the Sub-Committee of the Medical Research Council appointed to inquire into the question as a result of outbreaks of acute yellow atrophy in certain military hospitals during the war. In those there was the puzzling fact that suddenly cases of acute yellow atrophy had begun to crop up in hospitals where there had been no change in dosage for about eighteen months. Also, in the last I9 cases of jaundice occurring in his clinic at 
St. Thomas's Hospital, Dr. Clements's analysis had shown that in ro the dose of " $9 \mathrm{I} 4$ " had been no higher than 0.6 gramme, while in 3 the total dosage had ranged from $\mathrm{I} \cdot 05$ to $\mathrm{I} \cdot 95$, and in another 3 from 2.79 to 3.9 grammes. In the face of these facts one was bound to consider that there must be a powerful other factor, but what it was one could not say with any degree of certainty. Lately he had been interested in reading a paper by H. Ruge on jaundice occurring in the German Navy from I9I9 to I929 (Ruge, H., Dermat. Woch., I932, vol. 94, 278). In this paper Ruge traced the incidence of jaundice in the German Navy from 1908 to I929, and the interesting fact emerged that both ordinary jaundice and salvarsan jaundice were comparatively infrequent until about 1920 , after which it increased very considerably, reaching a maximum in 1923 at 27.92 per $\mathrm{I}, 000$ and then declining to 7.07 in 1929 . The incidence of salvarsan jaundice seemed to follow a closely parallel course, being approximately one-third to one-fifth of the total. The impression one gathered was that when jaundice is about, so to speak, salvarsan jaundice is also far more common, as if the arsenobenzene compound converted a latent jaundice into the manifest. Dr. Anwyl Davies had criticised Craven's experiments on the grounds that carbohydrates are bad for dogs. He (Colonel Harrison) could not claim any useful knowledge of a dog's dietary but his impression was that carbohydrates entered rather largely into it ; for example, dog's biscuits seem to be made up mostly of carbohydrates. He had noticed that in India his dogs seemed to thrive very well on chupatties and gravy, which constituted their ordinary dietary. He was bound to say that he had been greatly impressed by Craven's experiments. He had been interested to hear Mr. Lloyd remark on the great rarity of salvarsan jaundice in the women attending his clinic ; that had been exactly his experience at St. Thomas's Hospital. Sir William Willcox had mentioned two cases of severe symptoms following bismuth injections. $\mathrm{He}$ could not help thinking that in one of them, at any rate, the injection must have been inadvertently given into a vein in the gluteal region. The danger of this is a good reason for giving the injection deep subcutaneously rather than intramuscularly.

SiR William Willcox (in reply), said that he did not 
come forward as an expert on venereal diseases: the cases which came his way were those showing toxic symptoms following drugs used in treatment. He agreed with Dr. Nabarro that toxic jaundice was not very common in children. That was because their livers were more protected by glycogen, more care was taken in dosage, and they were more amenable to control, less liable to "dietetic indiscretions" than adults. He thought that Dr. Nabarro had been very wise in giving sulfarsenol in the case of the boy with cirrhosis of the liver. $\mathrm{He}$ knew that Colonel Harrison used to employ sulfarsenol a good deal. American work had shown that Nature had been very generous as regards the liver. There were something like twenty times as many liver cells for carrying on the requirements of the body as were really necessary, so that a person could live quite well with a quarter of the liver functioning.

$\mathrm{He}$ had not wished to suggest that bismuth was a dangerous liver poison; it very rarely produced jaundice alone, but he had seen that day a case in which a patient had had a mild course of novarsenobillon, the last dose being given last July, and then ten doses of bismuth had been given, one every fortnight since then, and the patient had just developed jaundice. He thought this must be due to the bismuth on the top of the salvarsan.

Dr. Davies had suggested that dermatitis had some association with the liver; he thought that was quite true. He had used liver extract in cases of toxic jaundice, and thought it very useful. He had been interested in the large doses of salvarsan given at the London Hospital, but he thought a three-weeks' break in the middle of the treatment was very valuable and saved the situation. He did not think one got anaphylaxis with NAB, at any rate, with intravenous injections.

Mr. Nicol had appeared to agree with him about tests for liver function. There was no quick sort of consultingroom test beyond the icterus-index test or the Van den Bergh reaction.

He agreed with Mr. Lloyd that toxic jaundice in women was exceedingly uncommon. He had seen only one or two cases of salvarsan jaundice in women. He had been interested in Mr. Lloyd's remarks on anthrax and the giving of $\mathrm{I}_{2}^{\frac{1}{2}}$ grammes $\mathrm{NAB}$ in thirty-six hours. In rat-bite and relapsing fever and in Vincent's angina 


\section{BRITISH JOURNAL OF VENEREAL DISEASES}

there were dramatic cures after using $\mathrm{NAB}$ in doses under the maximum, e.g., 0.4 gramme; with bacteria it was necessary to give big doses, and he had not been aware that it was of value in anthrax.

He agreed with Mr. Lloyd also in what he had said about calcium protecting the liver.

Colonel Ffrench had talked about the post-mortem changes in toxic jaundice. The picture described was a typical one of subacute necrosis. The shrunken liver and the necrosis made it quite a classical case.

Colonel Harrison had spoken of an X-factor, and the speaker quite agreed with him that this was very important. He had named it symbiosis. He had thought there were a number of X-factors, especially in men, who were not over-careful what they did after receiving the injection. It was really safer, if one was going to give salvarsan, to keep the patient in bed until the following midday. And to have the patient on a light diet for the twenty-four hours previous to the injection. No alcohol should be taken during this period, plenty of carbohydrates, fruit, and 2 or 3 ozs. of glucose should be taken.

W. H. Willcox. 